\title{
Prognostic significance of a positive radial margin after esophageal cancer resection
}

\author{
Sebastien Gilbert, MD, ${ }^{\mathrm{a}, \mathrm{b}}$ Andre B. Martel, BSc, ${ }^{\mathrm{c}}$ Andrew J. Seely, MD, PhD, ${ }^{\mathrm{a}, \mathrm{b}}$ \\ Donna E. Maziak, MD, MSc, ${ }^{a}$ Farid M. Shamji, MD, ${ }^{a}$ Sudhir R. Sundaresan, MD, ${ }^{a}$ and \\ P. James Villeneuve, MD, $\mathrm{PhD}^{\mathrm{a}, \mathrm{b}}$
}

\begin{abstract}
Objective: The prognostic significance of an incomplete esophageal cancer resection due to a positive microscopic radial margin remains unclear. The aim of this study is to examine the relationship between radial margin status and oncologic outcomes.
\end{abstract}

\begin{abstract}
Methods: We performed a retrospective review of esophageal cancer resections between 2004 and 2012. Radial margin status was defined according to the College of American Pathologists. Exclusion criteria were complete pathologic response $(n=12)$, positive proximal or distal margin $(n=11), R 2$ resection $(n=5)$, and carcinoma in situ $(\mathrm{n}=2)$.

Results: Of 154 patients, $30(19 \%)$ had a positive radial margin (RM+) and $124(81 \%)$ had a complete resection (R0). The 2 groups were similar with respect to age, gender, proportion of squamous tumors, middle thoracic tumor location, rate of neoadjuvant chemoradiation and adjuvant radiation, transhiatal approach, number of examined lymph nodes, and length of proximal and distal margins. In patients with stage III, the locoregional recurrence-free interval was similar between groups; however, RM+ was associated with a 17-month decrease in the median time to distant recurrence $(\mathrm{RM}+=7$ months [95\% confidence interval, 4-14]; $\mathrm{R} 0=24$ months [median not reached]; $P<.01$ ). The median survival was also significantly decreased by 12 months in the RM+ group $(\mathrm{RM}+=13$ months [ $95 \%$ confidence interval, 7-26]; $\mathrm{R} 0=25$ months [ $95 \%$ confidence interval, 20-30]; $P=.04)$.
\end{abstract}

Conclusions: An isolated, positive microscopic radial margin was associated with a greater risk for distant recurrence. There was no impact on locoregional disease control. The role of adjuvant, systemic therapy in patients with an isolated, microscopically $\mathrm{RM}+$ merits further evaluation. (J Thorac Cardiovasc Surg 2015; 149:548-55)

See related commentary on pages 556-7.

Removal of the primary tumor with an adequate margin of normal tissue is a basic tenet of surgical oncology. Incomplete resection generally equates to failed surgical therapy, except in selected situations in which tumor debulking may be of benefit to the patient. Despite meticulous surgical technique, anatomic constraints imposed on wide circumferential resection of the esophagus may predispose to incomplete tumor extirpation. The prognostic

From the Division of Thoracic Surgery, ${ }^{a}$ University of Ottawa, Ottawa, Ontario, Can-

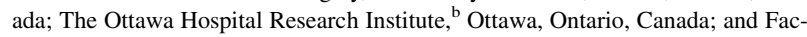
ulty of Medicine, ${ }^{\mathrm{c}}$ University of Ottawa, Ottawa, Ontario, Canada.

Disclosures: Authors have nothing to disclose with regard to commercial support.

Read at the 94th Annual Meeting of The American Association for Thoracic Surgery, Toronto, Ontario, Canada, April 26-30, 2014.

Received for publication April 11, 2014; revisions received Sept 9, 2014; accepted for publication Oct 6, 2014; available ahead of print Nov 21, 2014.

Address for reprints: Sebastien Gilbert, MD, Division of Thoracic Surgery, The Ottawa Hospital, University of Ottawa, General Campus Suite 6363, 501 Smyth Rd, Ottawa, Ontario K1H 8L6, Canada (E-mail: sgilbert@toh.on.ca).

0022-5223/\$36.00

Copyright (c) 2015 by The American Association for Thoracic Surgery

http://dx.doi.org/10.1016/j.jtcvs.2014.10.040 significance of incomplete esophageal cancer resection solely due to a microscopically positive radial resection margin is unclear. The problem is largely confined to patients with tumors that have transgressed the muscularis propria (ie, T3 or T4). These tumors are often associated with regional lymph node involvement, a strongly negative prognostic indicator that may obscure the effect of a positive radial margin $(\mathrm{RM}+)$ on survival. ${ }^{1}$ There are conflicting reports on the relationship between radial margin status and cancer survival. A recent meta-analysis suggests that an $\mathrm{RM}+$ is a poor prognostic indicator. ${ }^{2}$ There are still limited data on recurrence type and freedom from recurrence in patients with an RM+ after esophagectomy. The objective of this study was to compare the clinical characteristics and the oncologic outcomes of patients with esophageal cancer who had an incomplete resection solely due to an RM+ with those who underwent complete resection (R0). We hypothesized that in tumors of the same pathologic stage, an RM+ would be an independent, poor prognostic factor for local recurrence.

\section{MATERIALS AND METHODS}

After approval from the research ethics board, a retrospective review of all patients with esophageal cancer who underwent surgical 


$$
\begin{aligned}
& \text { Abbreviations and Acronyms } \\
& \qquad \begin{array}{ll}
\mathrm{CI} & =\text { confidence interval } \\
\mathrm{CT} & =\text { computed tomography } \\
\mathrm{PET} & =\text { positron emission tomography } \\
\mathrm{RM}+ & =\text { positive radial margin } \\
\mathrm{R} 0 & =\text { complete resection }
\end{array}
\end{aligned}
$$

resection was completed. Patient characteristics, treatment details, tumor histopathology, and follow-up data were extracted from medical records, de-identified, and stored in a prospectively maintained, encrypted database. The radial margin was deemed positive if malignant cells were identified at the inked margin in accordance with the guidelines of the College of American Pathologists. ${ }^{3}$ All margin and primary tumor measurements were obtained ex vivo after preservation with formalin, a process that has been associated with contraction of tissues and a $60 \%$ to $70 \%$ decrease in measurements obtained in vivo. ${ }^{4}$ The primary outcome of cancer recurrence was classified as local, regional, or distant. Recurrent cancer within the proximal esophagus or the esophageal replacement conduit was defined as local. Recurrences were labeled regional if they occurred within the lymphatic drainage of the esophagus and gastroesophageal junction, including the cervical, thoracic, and celiac axis lymph node basins. Lymph nodes in the regional drainage of the esophagus and gastroesophageal junction were deemed positive if the short-axis diameter exceeded $10 \mathrm{~mm}$ or the standard uptake value was reported as abnormal on positron emission tomography/computed tomography scan. All other recurrences were considered distant. Patients were routinely followed every 3 to 4 months after resection with a clinic visit and computed tomography scans of the chest, abdomen, and pelvis for recurrence monitoring. Recurrence-free (or disease-free) interval was defined as the period between the date of surgery and the identification of radiologic recurrence. Pathologic confirmation of recurrence was not mandatory. Overall survival was defined as the interval between the date of surgery and either death from any cause or loss to follow-up. Operations were performed using transhiatal or transthoracic (2- or 3-field) approaches. In patients who received neoadjuvant therapy, nodal status (ypN) was obtained from the surgical resection specimens. With the exception of the peritumoral region, we have been routinely dissecting lymph node-bearing adipose tissue from the surgical specimen before pathologic assessment to optimize the accuracy of lymph node count and obtain lymph node status information from different lymph node stations. This change in the preparation of the surgical specimen was implemented during the last 2 years of the study and had no statistically significant impact on the rate of RM+. Tumors were staged according to the Seventh Edition of the AJCC Cancer Staging Manual. ${ }^{5}$ All T4 tumors were T4a because they invaded the diaphragm at the level of the crura, the mediastinal pleural, or the pericardium.

\section{Statistical Analysis}

Recurrence-free and overall survival time analyses were performed using the Kaplan-Meier method. ${ }^{6}$ Statistical significance was assessed by log-rank test. Hazard ratios and confidence intervals (CIs) were obtained at $95 \%$ significance. Binary logistic regression analysis was used to develop univariate and multivariate models. These models describe the association of potential explanatory variables with the status of the radial margin. Independent variables analyzed included age,

\begin{tabular}{|c|c|c|c|}
\hline & \multicolumn{2}{|c|}{ Radial margin status } & \multirow[b]{2}{*}{$P$ value } \\
\hline & $\begin{array}{l}\text { Positive } \\
(\mathbf{n}=\mathbf{3 0})\end{array}$ & $\begin{array}{l}\text { Negative } \\
(n=124)\end{array}$ & \\
\hline \multicolumn{4}{|l|}{ Gender } \\
\hline Male & $27(90)$ & $92(74)$ & .09 \\
\hline Female & $3(10)$ & $32(26)$ & \\
\hline \multicolumn{4}{|l|}{ Age (y) } \\
\hline Mean & 63 & 66 & .15 \\
\hline Range & $33-90$ & $45-79$ & \\
\hline \multicolumn{4}{|l|}{ Histology } \\
\hline Adenocarcinoma & $24(77)$ & $99(80)$ & .07 \\
\hline Squamous cell & $4(13)$ & $23(19)$ & \\
\hline Other & $3(10)$ & $2(1)$ & \\
\hline \multicolumn{4}{|l|}{ Tumor location } \\
\hline Upper & - & $1(1)$ & 17 \\
\hline Middle & $2(7)$ & $10(8)$ & \\
\hline Lower & $5(16)$ & $46(37)$ & \\
\hline GEJ & $24(77)$ & $65(54)$ & \\
\hline \multicolumn{4}{|l|}{ Neoadjuvant therapy } \\
\hline Chemoradiation & $4(13)$ & $31(25)$ & .23 \\
\hline Chemotherapy & $7(22)$ & $15(12)$ & .90 \\
\hline \multicolumn{4}{|l|}{ Surgical approach } \\
\hline Transthoracic & $27(90)$ & $113(91)$ & .73 \\
\hline Transhiatal & $3(10)$ & $11(9)$ & \\
\hline Adjuvant radiation & $8(20)$ & $17(14)$ & .40 \\
\hline Adjuvant chemotherapy & $13(43)$ & $39(32)$ & .28 \\
\hline \multicolumn{4}{|l|}{ Pathologic stage } \\
\hline I & $1(3)$ & $40(32)$ & $<.01$ \\
\hline II & - & $34(28)$ & \\
\hline III & $29(97)$ & $50(40)$ & \\
\hline T3-T4 tumors & $30(100)$ & $62(50)$ & $<.01$ \\
\hline \multicolumn{4}{|l|}{ Lymph nodes } \\
\hline Resected & $16(8-26)$ & $14(9-22)$ & .69 \\
\hline Positive & $3(1-8)$ & $1(0-2)$ & $<.01$ \\
\hline Stage III tumors & $\mathrm{n}=29$ & $\mathrm{n}=50$ & \\
\hline No & $1(3)$ & $2(4)$ & .42 \\
\hline N1 & $13(45)$ & $20(40)$ & \\
\hline $\mathrm{N} 2$ & $7(24)$ & $20(40)$ & \\
\hline N3 & $8(28)$ & $8(16)$ & \\
\hline \multicolumn{4}{|l|}{ Dimensions* } \\
\hline Tumor diameter & $35 \mathrm{~mm}(25-50)$ & $29 \mathrm{~mm}(15-40)$ & .01 \\
\hline Tumor length & $50 \mathrm{~mm}(33-65)$ & $35 \mathrm{~mm}(20-50)$ & $<.01$ \\
\hline Proximal margin & $23 \mathrm{~mm}(23-42)$ & $33 \mathrm{~mm}(22-47)$ & .05 \\
\hline Distal margin & $35 \mathrm{~mm}(23-54)$ & $30 \mathrm{~mm}(20-45)$ & .18 \\
\hline Dimensions T3-T4 tumors & $\mathrm{n}=30$ & $\mathrm{n}=62$ & \\
\hline Tumor diameter & $35 \mathrm{~mm}(25-50)$ & $30 \mathrm{~mm}(24-42)$ & .11 \\
\hline Tumor length & $50 \mathrm{~mm}(33-65)$ & $35 \mathrm{~mm}(27-55)$ & .02 \\
\hline Proximal margin & $23 \mathrm{~mm}(23-42)$ & $33 \mathrm{~mm}(21-47)$ & .14 \\
\hline Distal margin & $35 \mathrm{~mm}(23-54)$ & $25 \mathrm{~mm}(17-40)$ & .08 \\
\hline
\end{tabular}
gender, use of neoadjuvant therapy, tumor characteristics (histology, location, length, diameter, and $\mathrm{T}$ stage) and surgical approach. By using the Cox proportional hazards model, we examined the impact of radial margin status, T3-4 status, $\mathrm{N}$ status, pathologic stage, tumor diameter,
TABLE 1. Patient and tumor characteristics $(n=154)$

Numbers in parentheses are percentages. GEJ, Gastroesophageal junction. *Measurements were taken from formalin-preserved pathology specimens. Tumor dimensions, margin sizes, and lymph node counts are median values with 25 th to 75 th percentile cutoffs in parentheses.

and tumor length on survival and recurrence. Discrete variables were analyzed for statistically significant differences using the Pearson chi-square method or Fisher exact test where appropriate. Continuous 
TABLE 2. Multivariate analysis of the impact of radial margin on oncologic outcomes in patients with stage III disease $(n=79)$

\begin{tabular}{|c|c|c|c|c|c|c|}
\hline & \multicolumn{2}{|c|}{ Locoregional recurrence } & \multicolumn{2}{|c|}{ Distant recurrence } & \multicolumn{2}{|c|}{ Overall survival } \\
\hline & HR $(95 \%$ CI $)$ & $P$ value & HR $(95 \%$ CI $)$ & $P$ value & HR $(95 \%$ CI $)$ & $P$ value \\
\hline $\mathrm{RM}+$ & $0.7(0.3-2.1)$ & .55 & $3.0(1.5-5.9)$ & $<.01$ & $2.2(1.1-4.6)$ & .03 \\
\hline Tumor diameter & $1.0(0.9-1.0)$ & .29 & $1.0(0.9-1.0)$ & .55 & $1.0(0.9-1.0)$ & .46 \\
\hline Tumor length & $1.0(1.0-1.1)$ & .06 & $1.0(1.0-1.1)$ & .98 & $1.0(1.0-1.1)$ & .67 \\
\hline
\end{tabular}

$C I$, Confidence interval; $H R$, hazard ratio; $R M+$, positive radial margin.

variables were compared using the independent samples Student $t$ test or the Mann-Whitney $U$ test where appropriate. All tests of significance were 2 -sided. Tumor dimensions and resection margin sizes are expressed as the median followed by the 25 th and 75 th percentile values. Survival data are presented as the median value $95 \%$ CI. When the median interval was not reached, the estimate is provided. Statistical calculations were performed using SPSS 21 (IBM, Armonk, NY) and SAS 9 (SAS Institute, Inc, Cary, NC).

\section{RESULTS}

\section{Patient and Tumor Characteristics}

From 2004 to 2012, 184 patients underwent esophagectomy for cancer. Exclusion criteria included complete pathologic response $(n=12), R 1$ resection with a positive proximal or distal margin $(n=11), R 2$ resection $(n=5)$, and carcinoma in situ $(\mathrm{n}=2)$. The remaining 154 patients were divided according to the status of the radial resection margin. Of these, 30 (19\%) had an incomplete resection due to an $\mathrm{RM}+$ with negative proximal and distal resection margins. The patients with an $\mathrm{RM}+$ were similar in many respects to the patients who underwent $\mathrm{R} 0$ resection, including mean age $(\mathrm{RM}+=63 \pm 1.6$ years; $\mathrm{R} 0=66 \pm$ 0.9 years; $P=.15)$, male gender $(\mathrm{RM}+=90 \%[27 / 30]$; $\mathrm{R} 0=74 \% \quad[92 / 124] ; P=.09)$, middle third tumors $(\mathrm{RM}+=7 \%[2 / 30] ; \mathrm{R} 0=8 \%[10 / 124] ; P=.17)$, histology, and transhiatal resection approach $(\mathrm{RM}+=10 \%[3 / 30]$; R0 $=9 \%$ [11/124]; $P=.73$ ) (Table 1). The proportions of patients who received neoadjuvant chemoradiation $(\mathrm{RM}+=13 \%$ [4/30]; R0 $=25 \%$ [31/124]; $P=.23)$ or adjuvant radiation $(\mathrm{RM}+=20 \%[8 / 30] ; \mathrm{R} 0=14 \%$ $[17 / 124] ; \quad P=.4)$ were also statistically similar regardless of radial margin status. In patients with stage III, there was also no statistically significant difference in the use of neoadjuvant chemotherapy, neoadjuvant chemoradiation, adjuvant chemotherapy, or adjuvant radiation between the 2 groups. The median proximal margin $(\mathrm{RM}+=23 \mathrm{~mm}[23-42] ; \mathrm{R} 0=33 \mathrm{~mm}[22-47] ; P=.05)$ and distal margin sizes $(\mathrm{RM}+=35 \mathrm{~mm}$ [23-54]; $\mathrm{R} 0=30 \mathrm{~mm}$ [20-45]; $P=.18$ ) were similar between groups. There were differences between incompletely resected and completely resected tumors. Tumors with an $\mathrm{RM}+$ were exclusively T3 or T4 $(\mathrm{RM}+=100 \%$ [30/30]; $\mathrm{R} 0=50 \%$ [62/124]; $P<.01)$ and were longer $(50 \mathrm{~mm}$ [33-65] vs $35 \mathrm{~mm}$ [20-50]; $P<.01)$ and wider in diameter (35 mm [25-50] vs $29 \mathrm{~mm} \mathrm{[15-40];} P=.01$ ). When the analysis of tumor dimensions was confined to T3 and T4 tumors only, the difference in tumor diameter was no longer significant, but tumors with an RM+ remained significantly longer. The odds an RM+ was increased significantly with

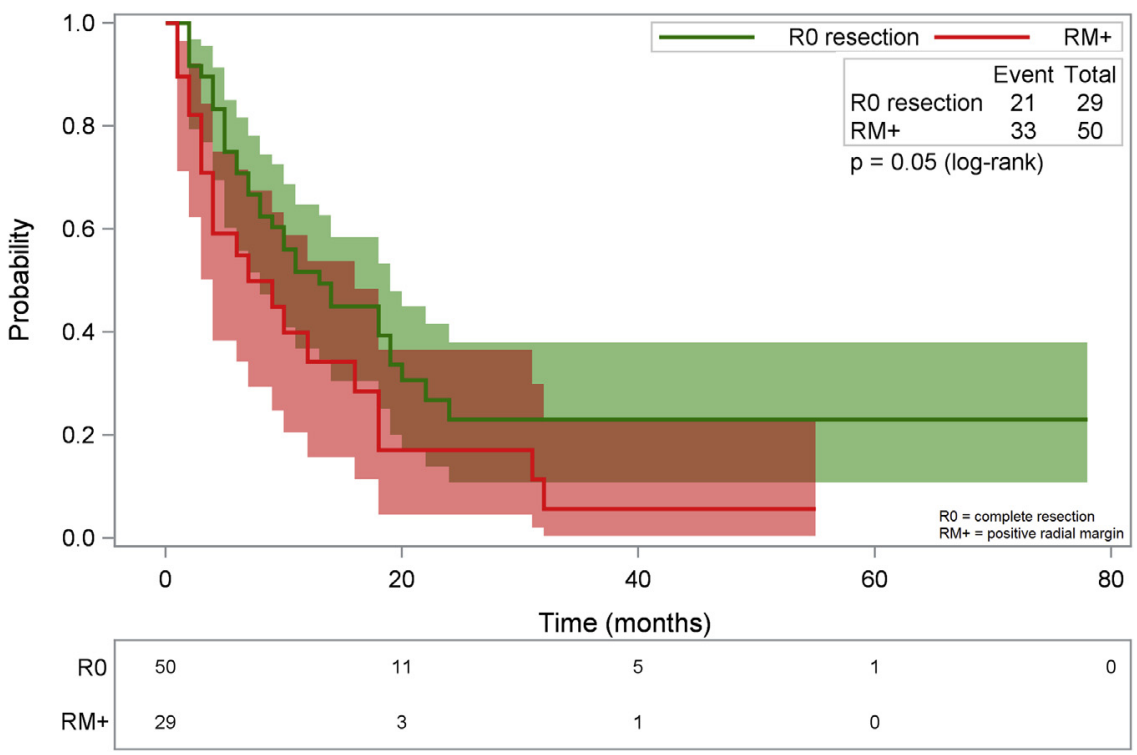

FIGURE 1. Freedom from recurrence in patients with stage III disease $(\mathrm{n}=79)$. Color bands represent CIs. $R M+$, Positive radial margin; $R 0$, complete resection. 


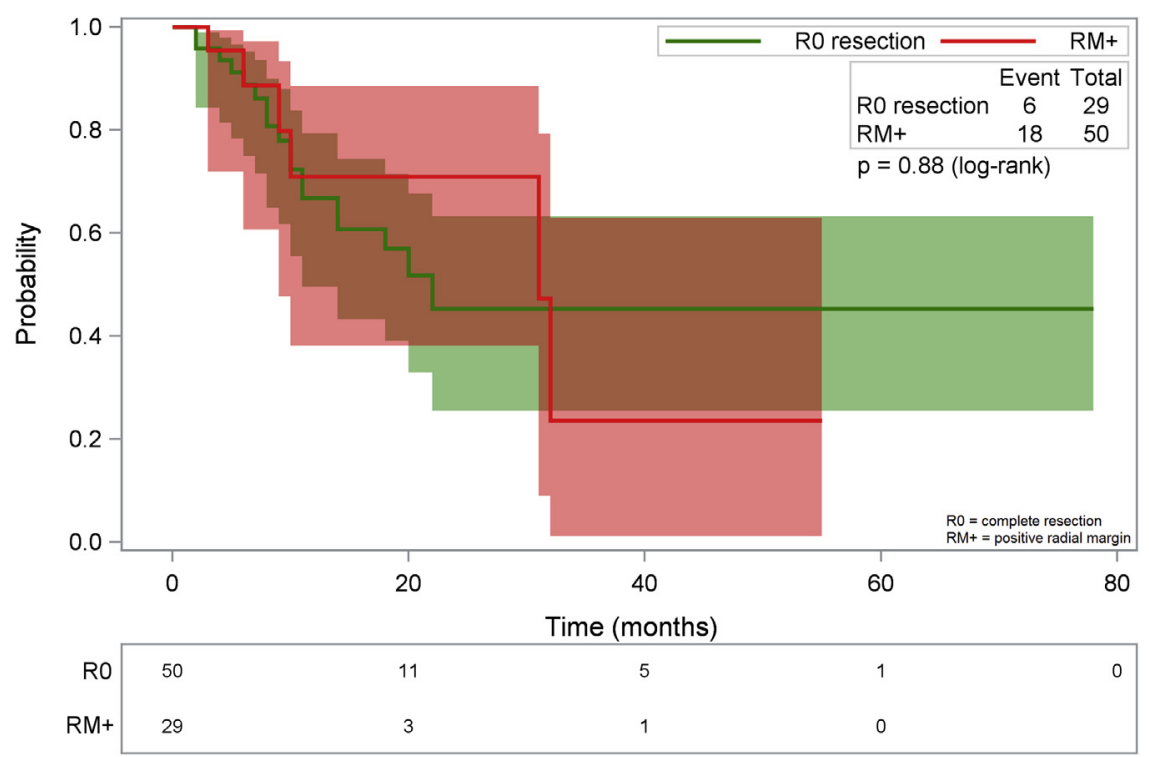

FIGURE 2. Freedom from locoregional recurrence in patients with stage III disease $(\mathrm{n}=79)$. Color bands represent CIs. $R M+$, Positive radial margin; $R O$, complete resection.

every $1-\mathrm{cm}$ increment in tumor length (odds ratio, 1.33 [95\% CI, 1.04-1.72]; $P=.02$ ). The median number of resected lymph nodes was similar in both groups $(\mathrm{RM}+=18 ; \mathrm{R} 0=17 ; P=.69)$. Tumors with an $\mathrm{RM}+$ were almost exclusively stage III $(\mathrm{RM}+=97 \%[29 / 30]$; $\mathrm{R} 0=40 \%$ [50/124]; $P<.01)$. The lone stage I tumor with a positive margin was a $\mathrm{T} 3 \mathrm{~N} 0$, well-differentiated squamous cell carcinoma of the lower esophagus. The median number of positive lymph nodes was significantly higher in the $\mathrm{RM}+$ group in the overall comparison $(\mathrm{RM}+=5 ; \mathrm{R} 0=2 ; P<.01)$. However, in patients with stage III, the median number of positive lymph nodes was similar $(\mathrm{RM}+=5 ; \mathrm{R} 0=4 ; P=.19)$ and so was the proportion of patients within each $\mathrm{N}$ descriptor category (N0-3). Surgical mortality was similar in both groups $(\mathrm{RM}+=3 \%[1 / 30] ; \mathrm{R} 0=2.4 \%[3 / 124]$; $P=.58)$.

\section{Cancer Recurrence and Overall Survival}

Some patients experienced more than 1 type of recurrence or were diagnosed with synchronous recurrences of different types (eg, locoregional and distant). The median follow-up

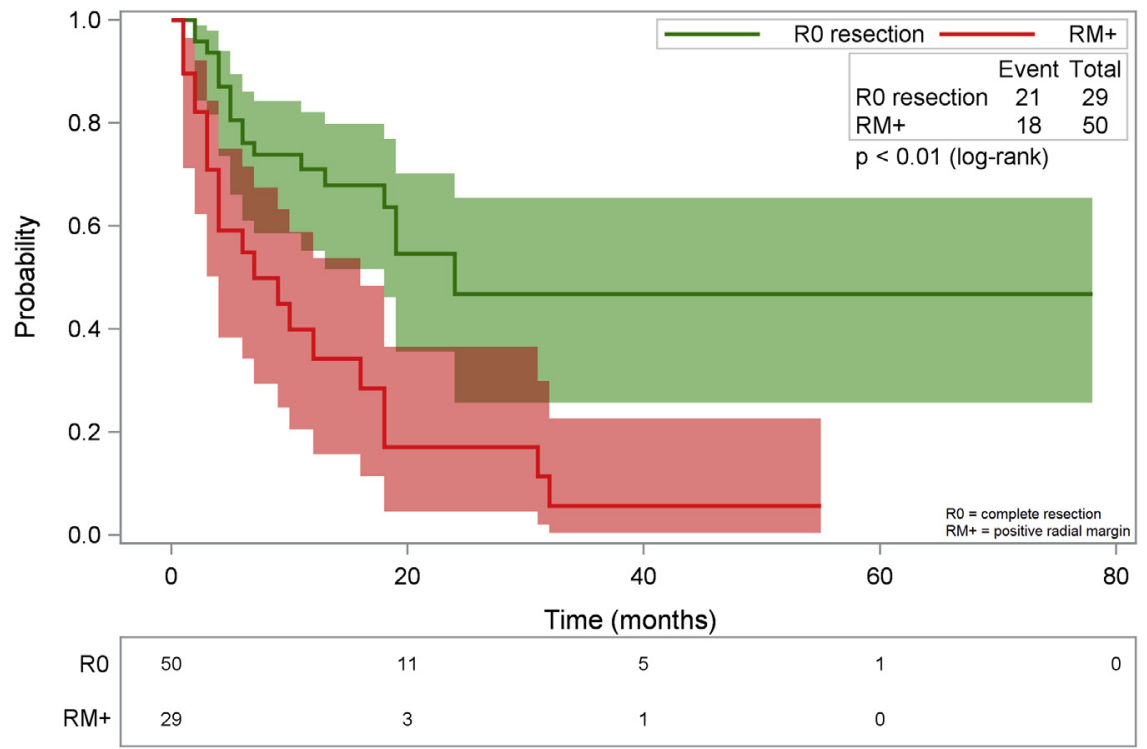

FIGURE 3. Freedom from distant recurrence in patients with stage III disease $(\mathrm{n}=79)$. Color bands represent CIs. $R M+$, Positive radial margin; $R 0$, complete resection. 
period was $14 \pm 2$ months for the $\mathrm{RM}+$ group and $25 \pm 2$ for the $\mathrm{R} 0$ group. Because patients in the RM+ group almost exclusively had stage III tumors $(97 \%)$, comparisons of oncologic outcomes between groups were confined to patients with stage III tumors. The relatively small number of patients in the RM+ group did not allow for statistical comparison of stage III subgroups (IIIA-C). However, there was no significant difference in the proportion of IIIA, IIIB, and IIIC tumors between the RM+ and R0 groups. We examined the effect of radial margin status, tumor diameter, and tumor length on oncologic outcomes using proportional hazards regression limiting the analysis to patients with stage III to control for the potential effect of Tand $\mathrm{N}$ status on oncologic outcomes. In patients with stage III esophageal cancer, an RM+ was associated with a significant increase in the likelihood of distant recurrence and mortality in both univariate and multivariate analyses (Table 2). Radial margin status, tumor diameter, and tumor length did not significantly affect the risk of locoregional recurrence. The median recurrence-free interval, including all recurrence types, was 9 months ( $95 \% \mathrm{CI}, 4-14)$ in the $\mathrm{RM}+$ group compared with 13 months $(95 \% \mathrm{CI}, 8-18)$ in the R0 group $(P=.05)$ (Figure 1). The median locoregional recurrence-free interval was 31 months $(95 \% \mathrm{CI}, 12-50)$ in the RM+ group compared with an estimated 22 months (median not reached) in patients with a negative radial margin $(P=.88)$ (Figure 2$)$. An $\mathrm{RM}+$ was associated with a significantly shorter freedom from distant recurrence than a negative radial margin $(\mathrm{RM}+=7$ months $[95 \% \mathrm{CI}$, 4-14]; R0 $=24$ months [median not reached]; $P<.01$ ) (Figure 3). Last, median survival was significantly decreased by 12 months in the $\mathrm{RM}+$ group $(\mathrm{RM}+=13$ months [95\% CI, 7-26]; R0 $=25$ months [95\% CI, 20-30]; $P=.04$ ) (Figure 4).

\section{DISCUSSION}

The results of our study did not support the hypothesis that a positive microscopic radial margin increases the risk of local recurrence after esophageal cancer resection. Also, an $\mathrm{RM}+$ did not influence the overall risk of recurrence or the freedom from locoregional recurrence. However, it was associated with a significantly higher probability of distant failure and a significant decrease in median overall survival of 1 year. Table 3 summarizes recently published series of $\mathrm{RM}+$ after esophagectomy with a sample size of at least 100 patients. $^{7-10,12,13,18-24}$ Most of the reports (10/13) used the Royal College of Pathologists' criteria, which require at least $1 \mathrm{~mm}$ of uninvolved tissue around the tumor for the radial margin to be deemed negative. These criteria are different than the College of American Pathologists' guidelines that were used in this study. A recent meta-analysis evaluating the clinical significance of radial margin status on survival concluded that the data were insufficient to accurately distinguish its potential effect on survival from the impact of nodal disease on overall prognosis. $^{2}$

In recent literature, the incidence of an $\mathrm{RM}+$ ranges from $17 \%$ to $50 \%$ ( $19 \%$ in this study). Published results are conflicting with regard to the prognostic implications of radial margins after esophagectomy. The use of different pathologic criteria makes comparisons between studies difficult and may explain the lack of consensus on the prognostic implications of an RM+ after esophagectomy. For instance, using the Royal College of Pathologists'

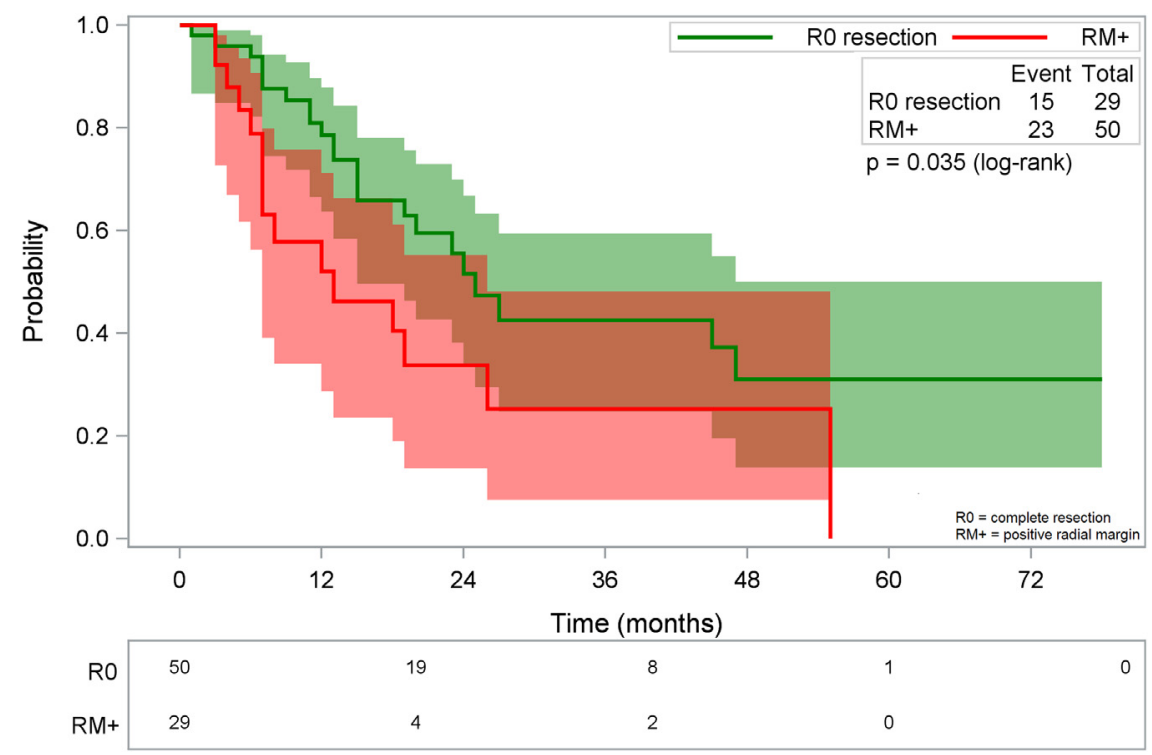

FIGURE 4. Overall survival in patients with stage III disease $(\mathrm{n}=79)$. Color bands represent CIs. $R M+$, Positive radial margin; $R O$, complete resection. 
TABLE 3. Literature on the prognostic significance of a positive radial margin after esophagectomy

\begin{tabular}{|c|c|c|c|c|c|c|c|c|c|c|c|c|}
\hline Author & $\mathbf{n}$ & Design & $\begin{array}{c}\text { Pathologic } \\
\text { criteria }\end{array}$ & $\mathbf{R M}+$ & SCC & $\begin{array}{c}\text { Neoadjuvant } \\
\text { therapy }\end{array}$ & THE & T3 & $\begin{array}{c}\text { Follow-up } \\
\text { (months) }\end{array}$ & $\begin{array}{l}\text { Impact on } \\
\text { recurrence }\end{array}$ & $\begin{array}{c}\text { Impact on } \\
\text { survival }\end{array}$ & Comments \\
\hline $\begin{array}{l}\text { Rao and } \\
\text { colleagues }^{8}\end{array}$ & 115 & $\mathrm{R}$ & RCP CAP & $57(50)$ & $31.3 \%$ & $32 \%$ & $0 \%$ & $68 \%$ & 38 & None & $\downarrow$ & \\
\hline $\begin{array}{l}\text { Harvin and } \\
\text { colleagues }\end{array}$ & 160 & $\mathrm{R}$ & RCP CAP & $42(26)$ & $0 \%$ & $100 \%$ & $14 \%$ & $100 \%$ & $?$ & None & None & \\
\hline $\begin{array}{l}\text { Reid and } \\
\text { colleagues }^{18}\end{array}$ & 269 & $\mathrm{R}$ & $\mathrm{RCP}$ & $102(38)$ & $25 \%$ & $62 \%$ & $?$ & $64 \%$ & 88 & $\uparrow(30 \%)$ & $\downarrow$ in T3-T4 & $\begin{array}{l}\text { Proportion of } \\
\text { positive lymph } \\
\text { nodes had no } \\
\text { effect on OS }\end{array}$ \\
\hline $\begin{array}{l}\text { Chao and } \\
\text { colleagues }\end{array}$ & 145 & $\mathrm{R}$ & RCP CAP & $25(17)$ & $100 \%$ & $100 \%$ & $0 \%$ & $100 \%$ & 50 & $\begin{array}{c}\uparrow \text { locoregional } \\
(24 \%) \\
\uparrow \text { distant } \\
(29 \%) \dagger\end{array}$ & $\downarrow$ & $\begin{array}{l}51 \% \text { positive } \\
\text { margin using } \\
\text { RCP criteria }\end{array}$ \\
\hline $\begin{array}{l}\text { Suttie and } \\
\text { colleagues }^{10}\end{array}$ & 350 & $\mathrm{R}$ & $\mathrm{RCP}$ & $70(20)$ & $29 \%$ & $8 \%$ & $19 \%$ & $?$ & $?$ & No data & $\downarrow$ & $\begin{array}{c}\text { THE has } \uparrow \text { risk of } \\
\text { positive margin }\end{array}$ \\
\hline $\begin{array}{c}\text { Mirnezami and } \\
\text { colleagues }^{19}\end{array}$ & 314 & $\mathrm{P}$ & $\mathrm{RCP}$ & $144(46)$ & $16 \%$ & $?$ & $61 \%$ & $?$ & $?$ & No data & None & \\
\hline $\begin{array}{l}\text { Scheepers and } \\
\text { colleagues }^{20}\end{array}$ & 110 & $\mathrm{R}$ & $\mathrm{RCP}$ & $42(38)$ & $24 \%$ & $28 \% *$ & $100 \%$ & $89 \%$ & $?$ & No data & $\downarrow$ in T3 & \\
\hline $\begin{array}{l}\text { Sillah and } \\
\text { colleagues }^{21}\end{array}$ & 320 & $\mathrm{R}$ & $\mathrm{RCP}$ & $89(28)$ & $20 \%$ & $39 \% *$ & $0 \%$ & $66 \%$ & $?$ & No data & $\downarrow$ & \\
\hline $\begin{array}{l}\text { Sujendran and } \\
\text { colleagues }^{22}\end{array}$ & 242 & $\mathrm{P}$ & $\mathrm{RCP}$ & $55(23)$ & $21 \%$ & $59 \% *$ & $31 \%$ & $60 \%$ & $?$ & $\begin{array}{c}\uparrow \text { locoregional } \\
(17 \%) \dagger\end{array}$ & $\downarrow$ & \\
\hline $\begin{array}{l}\text { Griffiths and } \\
\text { colleagues }^{12}\end{array}$ & 249 & $\mathrm{R}$ & $\mathrm{RCP}$ & $79(32)$ & $27 \%$ & $13 \% *$ & $?$ & $60 \%$ & $?$ & No data & $\begin{array}{l}\downarrow \text { if }<25 \% \\
\text { positive } \\
\text { lymph } \\
\text { nodes }\end{array}$ & \\
\hline $\begin{array}{l}\text { Mulligan and } \\
\text { colleagues }^{23}\end{array}$ & 212 & $\mathrm{R}$ & $\mathrm{RCP}$ & $49(23)$ & $38 \%$ & $49 \%$ & $?$ & $75 \%$ & 60 & None & $\begin{array}{l}\uparrow \text { OS if } \\
\text { neoadjuvant } \\
\text { therapy and } \\
\text { negative } \\
\text { margin }\end{array}$ & \\
\hline $\begin{array}{l}\text { Khan and } \\
\text { colleagues }^{24}\end{array}$ & 329 & $\mathrm{R}$ & $\mathrm{RCP}$ & $66(20)$ & $39 \%$ & $0 \%$ & $0 \%$ & $81 \%$ & $?$ & No data & None & \\
\hline $\begin{array}{l}\text { Dexter and } \\
\text { colleagues }^{13}\end{array}$ & 135 & $\mathrm{P}$ & $\mathrm{RCP}$ & $63(47)$ & $27 \%$ & $0 \%$ & $4 \%$ & $70 \%$ & 19 & No data & $\begin{array}{r}\downarrow \mathrm{OS} \text { if }<25 \% \\
\text { positive LN }\end{array}$ & $\begin{array}{l}\text { Middle third } \\
\text { tumors did not } \\
\text { have } \uparrow \text { risk } \\
\text { positive margin }\end{array}$ \\
\hline
\end{tabular}

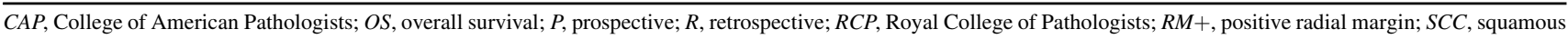
cell carcinoma; THE, transhiatal esophagectomy; $L N$, lymph node. *Neoadjuvant chemotherapy alone. $\dagger$ Percentages represent the approximate increase in reported incidence of recurrence associated with an $\mathrm{RM}+$.

guidelines has been demonstrated to significantly increase the proportion of patients with an $\mathrm{RM}+{ }^{7}$ Alternatively, the lack of agreement in the literature could be due to the relationship between an RM+ and lymph node involvement, which is a powerful predictor of oncologic outcomes. In this study, as in many others, a positive circumferential margin occurred mostly in patients with locally advanced, node-positive tumors, which are associated with a poorer prognosis. ${ }^{7,9,13,20,23,24}$ Information on the impact of radial margin status on locoregional and distant recurrence remains limited. Two of only 3 studies that used the College of American Pathologists' criteria showed no relationship between $\mathrm{RM}+$ and cancer recurrence. ${ }^{8,9}$ In this study cohort, the observed decrease in overall survival may be explained by the increased risk of developing distant metastasis.

Operative approach, tumor location, and neoadjuvant therapy may have an impact on the probability of an RM+ after surgery. ${ }^{10,11}$ These factors were all well balanced between the RM+ and R0 groups. Specific detail on lymph node status was available in only 2 studies showing that a positive margin negatively affected survival only when $25 \%$ or less of the total number of resected lymph nodes were involved. ${ }^{12,13}$ For patients 
with stage III disease in this study, an RM+ was associated with decreased overall survival despite an equivalent mean number of positive lymph nodes in both groups. Last, the information we obtained on the physical characteristics of tumors provides a new perspective on the risk of an RM+ after esophagectomy. It has been suggested that tumor length may have a significant impact on overall prognosis. ${ }^{14}$ In this study population, T3-4 tumors with an RM+ were significantly longer and associated with a poorer prognosis than completely resected T3-4 tumors.

\section{CONCLUSIONS}

We acknowledge that retrospective study results must be interpreted in light of their inherent biases. Because the comparison groups were similar in many respects, the poor outcomes observed suggest that an RM+ could be a clinical indicator of unfavorable tumor biology with increased propensity for distant metastases. Radical esophagectomy and neoadjuvant therapy are potential preventative measures to decrease the likelihood of a positive radial resection margin. More extensive local therapy using en bloc esophagectomy would likely incur the cost of increased perioperative morbidity and mortality. ${ }^{15}$ Neoadjuvant chemoradiation may improve resectability, but there are significant limitations, such as the inability to predict response to treatment, the probability of cancer progression while undergoing treatment, and the morbidity and mortality risks. ${ }^{16}$ In light of the study findings, postoperative radiation probably is probably not appropriate in this clinical setting because radial margin status had no impact on locoregional recurrence. Moreover, trials of adjuvant radiation in epidermoid carcinoma show that improved local control occurs at the expense of increased morbidity with no survival benefit. ${ }^{17}$ Adjuvant chemotherapy definitely should be given consideration in this particular situation, but we emphasize that clinical judgment needs to be exercised in selecting patients. Performance status, history of surgical complications, extent of nodal involvement, and objective evidence of response to neoadjuvant therapy are factors that we would take into account given their potential impact on the risk-benefit ratio of additional systemic therapy. More attention should be given to this particular subgroup of patients in future research on the multimodality treatment of esophageal cancer.

\section{References}

1. Rice TW, Rusch VW, Apperson-Hansen C, Allen MS, Chen L-Q, Hunter JG, et al. Worldwide esophageal cancer collaboration. Dis Esophagus. 2009;22: $1-8$.

2. Chan DS, Reid TD, Howell I, Lewis WG. Systematic review and meta-analysis of the influence of circumferential resection margin involvement on survival in patients with operable oesophageal cancer. Br J Surg. 2013;100: 456-64.

3. Washington K, Berlin J, Branton P, Burgart LJ, Carter DK, Fitzgibbons P, et al. Protocol for the examination of specimens from patients with carcinoma of the esophagus. CAP Today. 2012. Available at: http://www.cap.org/apps/docs/ committees/cancer/cancer_protocols/2012/Esophagus_12protocol_3111.pdf. Accessed November 10, 2014.

4. Siu KF, Cheung HC, Wong J. Shrinkage of the esophagus after resection for carcinoma. Ann Surg. 1986;203:173-6.

5. Edge SB, Byrd DR, Compton CC, Fritz AG, Greene FL, Trotti A III, eds. Esophagus and esophagastric junction. In: AJCC Cancer Staging Manual. 7th ed. New York: Springer; 2009:103-15.

6. Kaplan E, Meier P. Nonparametric estimation from incomplete observations. J Am Stat Assoc. 1958;53:457-81.

7. Chao Y-K, Yeh C-J, Chang H-K, Tseng C-K, Chu Y-Y, Hsieh M-J, et al. Impact of circumferential resection margin distance impact of circumferential resection margin distance after chemoradiotherapy in esophageal squamous cell carcinoma. Ann Surg Oncol. 2011;18: 529-34.

8. Rao VS, Yeung MM, Cooke J, Salim E, Jain PK. Comparison of circumferential resection margin clearance criteria with survival after surgery for cancer of esophagus. J Surg Oncol. 2012;105:745-9.

9. Harvin JA, Lahat G, Correa AM, Lee J, Maru D, Ajani J, et al. Neoadjuvant chemoradiotherapy followed by surgery for esophageal adenocarcinoma: significance of microscopically positive circumferential radial margins. $J$ Thorac Cardiovasc Surg. 2012;2:412-20.

10. Suttie SA, Nanthakumaran S, Mofidi R, Rapson T, Gilbert FJ, Thompson AM, et al. The impact of operative approach for oesophageal cancer on outcome: the transhiatal approach may influence circumferential margin involvement. Eur J Surg Oncol. 2012;38:157-65.

11. van Hagen $\mathrm{P}$, Hulshof MC, van Lanschot JB, Steyerberg EW, van Berge Henegouwen MI, et al. Preoperative chemoradiotherapy for esophageal or junctional cancer. N Engl J Med. 2012;366:2074-84.

12. Griffiths EA, Brummell Z, Gorthi G, Pritchard SA, Welch IM. The prognostic value of circumferential resection margin involvement in oesophageal malignancy. Eur J Surg Oncol. 2006;32:413-9.

13. Dexter SP, Sue-Ling H, McMahon MJ, Quirke P, Mapstone N, Martin IG. Circumferential resection margin involvement: an independent predictor of survival following surgery for oesophageal cancer. Gut. 2001;48: 667-70.

14. Wang BY, Goan YG, Hsu PK, Hsu WH, Wu YC. Tumor length as a prognostic factor in esophageal squamous cell carcinoma. Ann Thorac Surg. 2011;91: 887-93.

15. Altorki N, Skinner D. Should en bloc esophagectomy be the standard of care for esophageal carcinoma? Ann Surg. 2001;234:581-7.

16. Gilbert S, Gresham GK, Jonker DJ, Seely AJ, Maziak DE, Shamji FM, et al. Impact of patient selection, disease progression, and adverse events on esophageal cancer outcomes after trimodality therapy. Ann Thorac Surg. 2012;94: 1659-66.

17. Malthaner RA, Wong RK, Rumble RB, Zuraw L, Members of the Gastrointestinal Cancer Disease Site Group of Cancer Care Ontario's Program in Evidence-based Care. Neoadjuvant or adjuvant therapy for resectable esophageal cancer: a systematic review and meta-analysis. $B M C$ Med. 2004;2:35.

18. Reid TD, Chan DS, Roberts SA, Crosby TD, Williams GT, Lewis WG. Prognostic significance of circumferential resection margin involvement following oesophagectomy for cancer and the predictive role of endoluminal ultrasonography. Br J Cancer. 2012;107:1925-31.

19. Mirnezami R, Rohatgi A, Sutcliffe RP, Hamouda A, Chandrakumaran K, Botha A, et al. Multivariate analysis of clinicopathological factors influencing survival following esophagectomy for cancer. Int J Surg. 2010;8: 58-63.

20. Scheepers JJ, van der Peet DL, Veenhof AA, Cuesta MA. Influence of circumferential resection margin on prognosis in distal esophageal and gastroesophageal cancer approached through the transhiatal route. Dis Esophagus. 2009;22:42-8.

21. Sillah K, Pritchard SA, Watkins GR, McShane J, West CM, Page R, et al. The degree of circumferential tumour involvement as a prognostic factor in oesophageal cancer. Eur J Cardiothorac Surg. 2009;36:368-73.

22. Sujendran V, Wheeler J, Baron R, Warren BF, Maynard N. Effect of neoadjuvant chemotherapy on circumferential margin positivity and its impact 
on prognosis in patients with resectable oesophageal cancer. Br J Surg. 2008;95: 191-4.

23. Mulligan ED, Dunne B, Griffin M, Keeling N, Reynolds JV. Margin involvement and outcome in oesophageal carcinoma: a 10-year experience in a specialist unit. Eur J Surg Oncol. 2004;30:313-7.

24. Khan OA, Fitzgerald JJ, Soomro I, Beggs FD, Morgan WE, Duffy JP. Prognostic significance of circumferential resection margin involvement following oesophagectomy for cancer. Br J Cancer. 2003;88:1549-52.

\section{Discussion}

Dr Kernstine (Dallas, Tex). I want to reiterate what he is pointing out here, that it's kind of contrary to what we have been believing, that a positive microscopic margin should be treated with radiation therapy postoperatively, instead of what the authors are showing, that the patients should be treated with chemotherapy instead. Did you separate the patients with a positive microscopic margin into whether this was a direct extension of the disease versus a positive lymph node at the resection margin versus it being an intravascular or intralymphatic tumor at the margin?

Dr Gilbert. We do not have specific data on the proportion of $\mathrm{RM}+$ due to transection of a positive lymph node or an involved periesophageal blood vessel. We were concerned that dissection of lymph node stations from the surgical specimen immediately after retrieval and before formalin preservation would increase the rate of RM+. Our review indicated that there was no significant change in the incidence of RM+ since we started this intraoperative process. Detailed review of the pathology reports indicated that, with few exceptions, radial margin clearance was reported in relationship to the primary tumor, stating that it was present at the inked margin or at a specified distance in millimeters away from the inked margin. In most cases, the RM+ is the result of tumor extension to the plane of surgical resection. We acknowledge that in some instances, such as when the tumor extends to the mediastinal pleura, a positive radial resection margin may be inevitable.

Dr Kernstine. What was the role of positron emission tomography (PET) or PET computed tomography (CT) in evaluating these patients preoperatively, and is it possible that you could have introduced bias by its introduction into this series?

Dr Gilbert. In Ontario, esophageal cancer has been an approved indication for PET-CT scanning since 2009. Before that time, most patients underwent resection after a CT scan of the chest, abdomen, and pelvis. Since then, PET-CT scan before surgery has been routine. The limited accuracy of PET-CT and high-resolution $\mathrm{CT}$ in determining $\mathrm{T}$ status would make it challenging to estimate the risk of an RM+ status on the basis of imaging features. We looked for preoperative clinical predictors of an RM+, including age, gender, neoadjuvant therapy, surgical approach, tumor location, tumor length, and tumor diameter. On multivariate analysis, only tumor length remained significantly associated with an increased risk of an RM+. Although endoscopy is probably more accurate, this parameter could be estimated from a PET-CT.

Dr DeMeester (Los Angeles, Calif). We encounter this frequently because there is just pleura over these big tumors, so frequently it is very close. The pathologist will say it is within 1 $\mathrm{mm}$. Most of the time that is meaningless. To address the issue though, it might be useful to assess the frequency of pleural metastatic disease. How often did you see pleural metastatic disease perhaps related to a positive lateral resection margin in this series? This might help us understand the significance of the close or RM+ in patients with a distal esophageal tumor.

The second way is to look at the difference, if any, in overall survival. You showed basically no difference in locoregional recurrence. The difference was in distant disease. Further, you showed that an RM+ was associated with bigger, worse tumors. Can you look at patients with similar stage disease with and without an RM+ and see if that positive margin had any impact on their overall survival?

Dr Gilbert. As you pointed out, if radial margin status had a significant impact on local disease control, one would expect an $\mathrm{RM}+$ to be associated with a higher risk of locoregional recurrence. This was not the case in our study. Furthermore, you have accurately characterized our patient population by stating that recurrences within the pleural space are rare.

Regarding your second comment, the negative radial margin group included stage I and II cases. We reported that $97 \%$ of the patients with an RM+ had stage III disease. Therefore, all of the survival comparisons presented were confined to patients with stage III tumors. As you pointed out, it would be interesting to perform an analysis comparing stage IIIA, B, and C subgroups, but our current number of patients with an isolated RM+ is insufficient. This may be possible in the future as we accumulate more data. 